\title{
Mitochondrial Dysfunction in Alzheimer's Disease and the Rationale for Bioenergetics Based Therapies
}

\author{
Isaac G. Onyango, Jameel Dennis, Shaharyah M. Khan \\ Gencia Biotechnology, 706 B Forest St, Charlottesville, VA 22903, USA
}

[Received September 2, 2015; Revised October 6, 2015; Accepted October 7, 2015]

\begin{abstract}
Alzheimer's disease (AD) is a debilitating neurodegenerative disorder characterized by the progressive loss of cholinergic neurons, leading to the onset of severe behavioral, motor and cognitive impairments. It is a pressing public health problem with no effective treatment. Existing therapies only provide symptomatic relief without being able to prevent, stop or reverse the pathologic process. While the molecular basis underlying this multifactorial neurodegenerative disorder remains a significant challenge, mitochondrial dysfunction appears to be a critical factor in the pathogenesis of this disease. It is therefore important to target mitochondrial dysfunction in the prodromal phase of AD to slow or prevent the neurodegenerative process and restore neuronal function. In this review, we discuss mechanisms of action and translational potential of current mitochondrial and bioenergetic therapeutics for AD including: mitochondrial enhancers to potentiate energy production; antioxidants to scavenge reactive oxygen species and reduce oxidative damage; glucose metabolism and substrate supply; and candidates that target apoptotic and mitophagy pathways to remove damaged mitochondria. While mitochondrial therapeutic strategies have shown promise at the preclinical stage, there has been little progress in clinical trials thus far.
\end{abstract}

Key words: Alzheimer's disease, mitochondria, mitophagy, oxidative stress, neuroinflammation, mitochondrial biogenesis, neuroinflammation

Alzheimer's disease (AD) is the most common form of dementia and affects millions worldwide. It is characterized by severe memory loss, with episodic memory being particularly impaired during the initial phases. Most AD cases occur sporadically, although inheritance of certain susceptibility genes enhances risk. A role for dysfunctional mitochondria in $\mathrm{AD}$ pathogenesis has been postulated [1-3].

Cumulative evidence reveal that the regulation of mitochondrial turnover and function becomes impaired as a function of age in the brain and may contribute to neurodegeneration in AD [4]. Cerebral hypometabolism is evident in affected brain regions $[5,6]$ where mitochondrial structure is altered [7,8]. The expression and activity of mitochondrial enzymes important for metabolism, including cytochrome $c$ oxidase (COX), $\alpha$ ketoglutarate dehydrogenase complex, and pyruvate dehydrogenase complex is reduced [9-11]. AD brain mitochondria have reduced membrane potential, increased permeability, and produce excess reactive oxygen species (ROS) which damages proteins, lipids, and nucleic acids, and are believed to contribute to the pathogenesis of neurodegeneration. Growing evidence suggest that elevated amyloid- $\beta$ (A $\beta$ ) levels contribute to the mitochondrial abnormalities and although the mechanism is not clearly established, both amyloid precursor protein (APP) and $A \beta$ are found in mitochondrial membranes and interact with mitochondrial proteins. Overproduction of the APP and A $\beta$ may affect dynamics of mitochondrial fusion/fission [12-14], impair mitochondrial transport, disrupt the electron transfer chain, increase ROS production [15-17], and impair mitochondrial function [18-20]. These findings build a strong case for mitochondrial dysfunction

*Correspondence should be addressed to: Isaac G. Onyango DVM, PhD, Gencia Biotechnology, 706 B Forest

St, Charlottesville, VA 22903, USA. E-mail: ionyango@genciabiotech.com

ISSN: 2152-5250 
in $\mathrm{AD}$ and effective treatment will likely include targets that address mitochondrial function [21-23].

\section{Mitochondrial Biogenesis}

Mitochondrial biogenesis plays an essential role in maintaining an adequate functional neuronal mitochondrial mass by compensating for damaged mitochondria that have been eliminated. It is highly regulated and requires coordination and crosstalk between the nuclear and mitochondrial genomes [24]. While mitochondrial biogenesis occurs on a regular basis in healthy cells where mitochondria constantly divide and fuse with each other [25-27]; it also occurs in response to oxidative stress, increased energy demand, exercise training and certain diseases. The status of mitochondrial biogenesis in AD neurons is unclear [28]. Biogenesis is induced by the peroxisome proliferator-activated receptor $\gamma$ coactivator-1 $\alpha$ (PGC-1 $\alpha$ ) which activates different transcription factors, including nuclear respiratory factors 1 and 2 proteins (NRF-1 and NRF-2) and the mitochondrial transcription factor A (TFAM) [4, 29, 30];[28]. NRF-1 and NRF-2 regulate transcription of nuclear and mitochondrial genes involved in OXPHOS, electron transport (complex I-V), mtDNA transcription/replication, heme biosynthesis, protein import/assembly, ion channels, shuttles, and translation [31].

NRF-1 or NRF-2 also contribute to expression of nuclear encoded genes involved in biogenesis including [32] factor A (TFAM), mitochondrial transcription factor $\mathrm{B} 1$ or B2 (TFB1M or TFB2M), and mitochondrial RNA polymerase (POLRMT), and mitochondrial transcription termination factor (MTERF), mitochondrial DNA helicase (TWINKLE), single-stranded DNA-binding protein (mtSSB), and POL $\gamma \mathrm{B}$ [33] [34] but not POL $\gamma \mathrm{A}$ and MTERF3 [34]. When newly formed daughter mitochondria have been incorporated into the mitochondrial network, mitochondria that have been damaged or that have lost membrane potential are specifically targeted for degradation via an autophagylike process termed as mitophagy [35, 36]. Mitochondrial biogenesis is thought to be impaired in $\mathrm{AD}$ where the quantity of mitochondria as well as levels of NRF 1, NRF 2 , and TFAM along with nuclear levels of PGC- $1 \alpha$ are reduced in hippocampal tissues from $\mathrm{AD}$ brain compared to age matched control brain [37] [38] [39].

PGC- $1 \alpha$ activity at both the transcriptional and posttranslational level is modulated by the nutrient supply and energy balance within the cell [40] and mitochondrial damage [41] [42]. Furthermore, PPARs, mTOR (acting on YY1), and CREB (downstream of PKA signaling) transcriptionally activate PGC- $1 \alpha$ to initiate mitochondrial biogenesis [40]. At the post-translational level, PGC- $1 \alpha$ is regulated by both phosphorylation and acetylation events. AMP-dependent kinase (AMPK) can phosphorylate and activate PGC- $1 \alpha$ while GCN5mediated acetylation inhibits PGC- $1 \alpha$ activity [40]. Deacetylation of PGC- $1 \alpha$ by NAD + dependent SIRT 1 promotes mitochondrial biogenesis and ensures that the activity of PGC- $1 \alpha$ is sensitive to both the energy and the redox balance in the cell [32]. PGC- $1 \alpha$ co-activation of ERR $\alpha$ in turn promotes expression of mitochondrial SIRT3 that ensures effective scavenging of ROS at the mitochondria through activation of mitochondrial superoxide dismutase, amongst other mitochondrial sirtuin targets [43]. PARIS, a Parkin substrate, represses mitochondrial biogenesis by transcriptionally inhibiting PGC-1 $\alpha$ expression [44].

\section{Mitophagy}

Mitophagy is the process by which damaged or dysfunctional mitochondria are selectively engulfed by autophagosomes and delivered to lysosomes to be degraded and recycled by the cell [45]. An excess of reactive oxygen species (ROS) may function as an autophagy trigger [46] and dysfunctional mitochondria that overproduce ROS, are indeed selectively targeted for mitophagy [46].

Central to mitochondrial and cellular homeostasis, mitophagy is modulated by the PTEN-induced putative kinase 1 (PINK1)/Parkin pathway [47] which primarily targets mitochondria devoid of membrane potential $(\Delta \Psi \mathrm{m})$. PINK1 accumulate on the outer membrane of dysfunctional mitochondria and recruit the E3 ubiquitin ligase Parkin [48] [49] [50] that ubiquitinate several OMM proteins that are consequently targeted by P62/SQSTM1 [51].

P62 recognizes ubiquitinated substrates and directly interacts with autophagosome-associated LC3 to recruit autophagosomal membranes to the mitochondria [52]. Damaged mitochondria can also, independently of Parkin, increase FUNDC1 and Nix expression to recruit autophagosomes to mitochondria via direct interaction with LC3 [53] [54]. Ubiquitin ligases, like Smurf1, target depolarized mitochondria for mitophagy [55-57].

The transcription factor nuclear factor erythroid 2related factor 2 (Nrf2) partly regulates P62 expression due to the presence of an antioxidant response element (ARE) in its promoter region [58, 59]. Electrophilic natural products such as isothiocyanate compound, sulforaphane which upregulate Nrf2 by interfering with its regulator protein, the redox sensitive ubiquitination facilitator Keap1 (Kelch-like ECH-associated protein 1) can potentially induce P62 expression [60-62]. P62-mediated mitophagy inducer (PMI) (HB229), was recently developed to upregulate P62 via stabilization of Nrf2 and 
promote mitophagy. This compound bypasses the upstream steps of the mitophagic cascade and acts independently of the $\Delta \Psi \mathrm{m}$ collapse, and does not mediate any apparent toxic effects on mouse embryonic fibroblast (MEF) cells at the concentrations used in the assays [63]. Parkin also modulates transport of mitochondria along microtubules to a perinuclear region where autophagosomes are concentrated [64] [48]. This is likely due to Parkin-mediated turnover of Miro, a protein required to tether kinesin motor protein complexes to the OMM [65]. HDAC6, a ubiquitin-binding protein deacetylase is also recruited to mitochondria by Parkin [66] along microtubules [67, 68]. Mitophagy is crucial for cellular homeostasis and its impairment is linked to several neurodegenerative diseases [69] [70]. However, selective pharmacologic modulators of mitophagy that would facilitate dissection of the molecular steps involved in the removal of mitochondria from the network via this pathway are not presently available.

\section{Mitochondrial Fission}

Mitochondrial fission occurs during mitochondrial biogenesis when intramitochondrial components are sorted and split into daughter mitochondria [71, 72] but also precedes the selective targeting of mitochondria for mitophagy or cellular apoptosis [73-76].

Dynamin-related protein 1 (Drp1), a member of the dynamin family of GTPases, is the major protein involved in the division of membranes through translocation from the cytosol to the outer mitochondrial membrane where constricting rings are formed [77]. While fission occurs regardless of mitochondrial membrane potential, it is upregulated following mitochondrial depolarization, oxidation or nitrosylation, and ETC inhibition which trigger posttranslational modifications, including phophorylation, S-nitrosylation, ubiquitylation, and sumoylation on Drp1[66, 78] which result in mitochondrial fragmentation $[79,80]$.

Drp1 lacks a pleckstrin-homology domain and requires membrane receptor proteins such as Fis1 to facilitate its association and polymerization at membranes. It can cause Bax oligomerization independent of its GTPase activity [81] while the antiapoptotic Bcl-XL promotes mitochondrial fission in neurons through interactions with Drp1 that promote its GTPase activity [82].

In $\mathrm{AD} A \beta$ overproduction is associated with increased number of fragmented mitochondria, increased oxidative stress and loss of $\Delta \psi_{\mathrm{m}}$ and ATP production that is associated with increased expression of Drp1 [83]. Accumulated $A \beta$ enhances Drp1 activity in neurons by increasing Drp1 S-nitrosylation at Cys644. Likewise, AD patients are characterized by having $A \beta$-Drp 1 mediated mitochondrial fragmentation, mtDNA mutations [84] and decrease in oxphos [85].

Mdivi-1, a small molecule noncompetitive inhibitor of Drp1 GTPase activity that attenuates Drp1 mediated mitochondrial-fission in response to pro-apoptotic stimuli [86], has been developed and may potentially have therapeutic utility. Mdivi-1 application in vivo has been shown to for example protect cardiomyocytes against ischemia/reperfusion injury and attenuate retinal ganglion cell death after ischemic injury [87-89]. Mdivi-1 also partially rescues the mitochondrial damage due to inactivation of PINK1 [90]. Further research targeting therapeutics aimed at preserving mitochondrial function for the treatment of disease and injury may lead to improved clinical outlook for neurodegenerative diseases such as AD.

\section{Mitochondrial Membrane Potential}

The mitochondrial membrane potential $\left(\Delta \psi_{\mathrm{m}}\right)$ is created when protons are pumped from the mitochondrial matrix to the intermembrane space as electrons pass through the ETC and as a prerequisite for oxidative phosphorylation. However, the higher (more polarized) $\Delta \psi_{\mathrm{m}}$, the more mtROS is generated presumably due to the slowed electron transport [91] [92] [93]. Indeed, ROS generation is decreased when $\Delta \psi_{\mathrm{m}}$ is dissipated by either expressing mitochondrial uncoupling proteins (UCPs) [94] or using chemical uncouplers (Reynolds and Hastings, 1995), such as carbonyl cyanide p-(tri-fluromethoxy)phenylhydrazone (FCCP) [95] [96]. Small decreases in membrane potential (mild uncoupling) can reduce ROS formation by limiting the life span of reduced electron transport chain (ETC) intermediates capable of generating ROS, in addition to decreasing local oxygen tensions [9799] [100]] without seriously compromising cellular energetics [98, 100]. However, several AD animal models, and AD patient brains show evidence of reduced ATP levels, declined complex IV activity, enhanced oxidative stress compared to controls [101] [102, 103] and decreased $\Delta \psi_{\mathrm{m}}$ has been shown in AD animal models and in human cortical neurons ex vivo [102, 104, 105]. A redox-optimized ROS balance hypothesis, which states that physiological ROS signaling occurs within an optimized mitochondrial membrane potential, and oxidative stress can happen at either the extreme of high $\Delta \psi_{\mathrm{m}}$ or low $\Delta \psi_{\mathrm{m}}$ ([106] has been proposed to reconcile this obvious discrepancy. It is based on the fact that the redox couples involved in substrate oxidation (NADH) are closely linked to the redox couples involved in antioxidant defenses (NADPH). It is therefore vital to balance an adequate level of $\Delta \psi_{\mathrm{m}}$ to maintain matrix $\mathrm{NADPH}$ rather than $\mathrm{NADP}^{+}$, which is necessary for mitochondrial antioxidant enzyme systems. This means 
that an increase in mitochondrial uncoupling of the ETC can increase ROS production primarily because the antioxidant system of the cell is compromised. It has now been shown that ROS can stimulate mitochondrial uncoupling [107, 108] and that the processes of uncoupling and ROS generation exist in a feedback loop [109] [108, 110].

Fatty acid (FA) cycling across the inner mitochondrial membrane is an important endogenous mild uncoupling pathway that prevents ROS release [111, 112]. In the proton-rich intermembrane space, FA anions are protonated, become uncharged and flip-flop across the inner membrane lipid bilayer. Once in the mitochondrial matrix, the proton is released and the FA anion transported back to the intermembrane space by anion carriers, which include mitochondrial uncoupling proteins [113] [114], and the adenine nucleotide translocator [112] $[115,116]$. Post-ischemic tissue survival in the brain has been shown to closely correlate with uncoupling proteins expression [117].

\section{Mitohormesis}

While ROS can generate detrimental oxidative damage, they also play a crucial role in numerous signaling and stress responses [118, 119]. Mild oxidative stress may in fact promote longevity and metabolic health through the concept of mitochondrial hormesis (mitohormesis).

Mitohormesis occurs when low levels of oxidative stress induced by either caloric restriction, exercise [120], or other stimuli trigger an adaptive response that improves overall stress resistance. This is likely via increased endogenous antioxidant defense, which eventually reduces chronic oxidative damage [121] and extends lifespan. Inhibition of glycolysis, impairment of insulinlike signaling and certain mutations in mitochondrial ETC components, are also conditions that may promote longevity via ROS-dependent mitohormesis [122]. Glucose restriction induces mitochondrial respiration and increases oxidative stress and extends $C$. elegans lifespan via the AMPK- pathway in a manner that is sensitive to the antioxidant $\mathrm{N}$-acetyl cysteine, suggesting that oxidative stress is required for lifespan extension by dietary restriction [123]. Also treatment of C. elegans with low doses of the superoxide generating compound paraquat extend their lifespan [124].Mild inhibition of mitochondrial respiration extends the lifespan of organisms as diverse as yeast, worms, flies and mice [125] [126] [127] presumably through ROS stimulated HIF-1 activation of gene expression that promote longevity [128]. Mild mitochondrial insults may also communicate a stress response to induce the expression of mitochondrial chaperones such as HSP-6 and HSP-60. This mitochondrial unfolded protein response (UPR ${ }^{\mathrm{mt}}$ ) is thought to extend the life span of C. elegans by inhibiting the ETC $[129,130]$. However, deletion of atfs-1, encoding for a transcription factor required for the induction of the UPR ${ }^{\mathrm{mt}}$, does not avoid lifespan extension after inhibition of the ETC [129, 130], and constitutive activation of the UPR ${ }^{\mathrm{mt}}$ by gain of function mutations in atfs- 1 does not extend lifespan [131]. These along with complementary evidence obtained from diverse model organisms, has led to the mitohormesis model [129].

Although the evidence of mitohormesis in lifespan regulation in mammalian models is still lacking its translational implications should be considered as an ideal antioxidant therapy that prevents oxidative damage induced under pathological conditions without interfering with ROS needed for hormesis and cellular signaling.

\section{Caloric Restriction}

Caloric restriction (CR) involves consuming 20-40\% lower calories than normal has been suggested as a promising intervention to increase both median and maximal lifespan in humans (Peterson et al, 2012). It can prevent or delay several diseases including cancer, cardiovascular diseases, neurodegenerative disorders, diabetes and autoimmune diseases [132] and has been reported to protect against age-related mitochondrial dysfunction [133] and reduce mtDNA damage [134]. In animal models of neurodegenerative diseases it promotes neurogenesis and enhances synaptic plasticity [135], improves cognitive capability, anti-inflammatory mechanisms, reduce neural oxidative stress, induce various stress and neurotrophic/neuroprotective factors and prevents $\mathrm{A}$ neuropathology in $\mathrm{AD}$ transgenic models [136]. At the cellular level, CR alters $\Delta \psi_{\mathrm{m}}$ and respiratory activity, which results in lower ROS generation and oxidative damage. CR also increases mitochondrial biogenesis and bioenergetic efficiency through Akt, which directly phosphorylates and activates endothelial nitric oxide synthase (eNOS) leading to nitric oxide (NO) production [137, 138] [139] [140, 141] [142]. $\mathrm{NO}$ activates a NO/cGMP-dependent signaling pathway that induces PGC-1 $\alpha$, increasing mitochondrial biogenesis [143, 144]. This increase in mitochondrial biogenesis elicits the beneficial effects of CR [138, 139, 142, 143]. Mice on 3 months CR have higher levels of mitochondrial DNA, PGC-1 $\alpha$, NRF-1, Tfam, expression of cytochrome $\mathrm{c}$ oxidase, and cytochrome $\mathrm{c}$ when compared with mice fed ad libitum, indicating increased mitochondrial biogenesis [139]. 2,4-dinitrophenol, a CR mimetic induces similar results [142]. Long term exposure to elevated ROS levels impairs eNOS activity $[145,146]$. As a result eNOS functions in a negative feedback loop preventing the generation of excessive ROS. In a CR trial CALERIE based on $25 \% \mathrm{CR}, \mathrm{CR}$ 
patients were shown to have less mtDNA damage, more mtDNA content, and increased expression of some antioxidant enzymes, suggesting that $\mathrm{CR}$ improves mitochondrial function and delays mitochondrial aging through reducing oxidative stress. The increase in expression of several proteins involved in mitochondrial biogenesis such as PGC- $1 \alpha$, Tfam, and SIRT1 was reported in CR patients compared to controls [147]. CR also attenuates the age-related decline of autophagy by activating Sirt1 which deacetylates autophagy proteins [148-150] and this is associated with increased longevity as inefficient mitochondria are replaced with new functional mitochondria $[151,152]$. The net result is that $\mathrm{CR}$ reduces oxidative stress and enhances mitochondrial biogenesis in order to produce mitochondria that are more efficient in ATP production, have optimal oxidative capacity, and generate less ROS.

\section{Exercise}

Exercise training alone or in combination with CR may also represent an efficient strategy to delay mitochondrial aging and age-related dysfunction in humans through mechanisms stimulating mitochondrial biogenesis and oxidative capacity and improving protein quality control [153]. Skeletal muscle biopsies of humans performing high- intensity interval training showed an increase in Sirt1, nuclear PGC-1 $\alpha$ and Tfam, which lead to an increase in skeletal muscle mitochondria and improved exercise performance [154-156]. Biopsies performed in older men showed that even with aging, exercise increases mitochondrial DNA and mitochondrial respiratory chain activity which is likely related to increases in mitochondria biogenesis [157, 158]. While exercise training optimized mitochondrial function in elderly individuals [159] [160] when combined with a low carbohydrate (glycogen) diet increases the expression of PGC- $1 \alpha$ to optimize the oxidative capacity of human skeletal muscle [161]. In the CALERIE trial, CR with exercise training resulted in a $38 \%$ reduction in the estimated risk of cardiovascular disease, an important age-associated pathology, compared to controls [162]. Indeed, increased physical activity or even simply adopting active style habits may clearly reduce the rate of mitochondrial decline and attenuate the age-related phenotype. This exercise-induced increase in mitochondrial biogenesis is mediated through ROS as demonstrated by oral administration of antioxidants to rats impairs the exercise-induced increase in mRNA and protein levels of PGC-1 $\alpha$, NRF-1 and Tfam and cytochrome c [163]. Similar observations are made in humans. The exercise induced increase in PGC- $1 \alpha$ and PGC-1 $\beta$ ameliorate insulin resistance and initiate an adaptive response promoting endogenous antioxidant defense capacity. However, when the subjects diet was supplemented with antioxidants these effects were not observed [120]. Importantly, it was found that exercise training also increases brain mitochondrial biogenesis (mtDNA, and PGC-1 $\alpha$, SIRT1, and citrate synthase) and this may have important implications, not only with regard to fatigue, but also with respect to various central nervous system diseases and age-related dementia that are often characterized by mitochondrial dysfunction [153]. Therefore, exercise could be considered as a therapeutic option to reduce the negative effects of aging and decrease the risk of $\mathrm{AD}$.

\section{Mitochondrial Stress Response Signaling}

Mitochondria are the major source of cellular ROS and hence stress signaling that induces cellular senescence and apoptosis [118] [164] [165, 166] [167]. One of the major consequences of increased ROS and altered cellular redox state is the oxidation of thiol groups in cysteine residues in relevant proteins [118]. FoxO transcription factors are activated in response to elevated ROS levels to induce anti-oxidant responses (increased expression of catalase and SOD2), cell cycle arrest and/or cell death [168, 169]. Kinases that modulate cellular stress responses include mitochondrial Akt, GSK-3 $\beta$, PKA, Abl, PKC, Src and Atm [170] [171-177]. Akt phosphorylates and inactivates GSK-3 $\beta$, which can localize to the mitochondria. Mitochondrial GSK-3 $\beta$ phosphorylates MCL-1 and VDAC [174, 178] Sheldon et al., 2011) leading to MCL1 degradation and inducing apoptosis [178]; while phosphorylation of VDAC by GSK-3 $\beta$ results in increased mitochondrial membrane permeability, again predisposing to apoptosis $[174,179]$. GSK-3 $\beta$ is also known to phosphorylate and promote the proteasomal degradation of c-Myc, cyclin D1, and $\beta$-catenin [180, 181] [182]. PKA can be translocated to mitochondria by hypoxia and other physiological stresses [183, 184] where it associates with the mitochondria through Rab32 and other A-kinase AKAPs [171] and phosphorylates VDAC [172], Drp1 [183], and other mitochondrial proteins. For example, hypoxia destabilizes AKAP121 through induction of SIAH2, a mitochondrial ubiquitin ligase, thereby limiting oxidative capacity under conditions of low oxygen. Interestingly, AKAP121 also appears to promote mitochondrial localization of Src-tyrosine kinase [185] where Src appears to regulate CO activity and respiratory activity [185] [186], and other mitochondrial substrates for Src family kinases are likely [187]. Increased ROS induces protein kinase $\mathrm{C}$-delta $(\mathrm{PKC} \delta$ ) association with the mitochondria and this in turn recruits other signaling molecules, including the Abl tyrosine kinase that is associated with loss of membrane potential and non-apoptotic cell death [175]. Impaired oxidative 
metabolism and decreased ATP levels in neurons activate AMPK [188]. AMPK can also be activated by drugs such as metformin that inhibits complex I or resveratrol that inhibits the F0F1 ATPase [170]. AMPK modulates mitochondrial metabolism and targets Acetyl CoA carboxylase-2 (ACC2) to the OMM where it regulates lipid metabolism by controlling production of malonyl CoA [170]. AMPK therefore plays a key role in mitochondrial homeostasis by ensuring that only functionally viable mitochondria are retained. Upon its activation it induces not only mitochondrial biogenesis through activation of PGC-1 $\alpha[189,190]$ but also initiates mitophagy through ULK1 activation and mTOR inhibition [183, 191]. ATM kinase inhibition has been shown to cause CNS neurodegeneration in animal models [192]. ATM kinase, which is partly located at the mitochondria, is activated upon mitochondrial uncoupling [193] and while its mitochondrial substrates are not known, loss of ATM in genetically engineered mouse models leads to mitochondrial dysfunction.

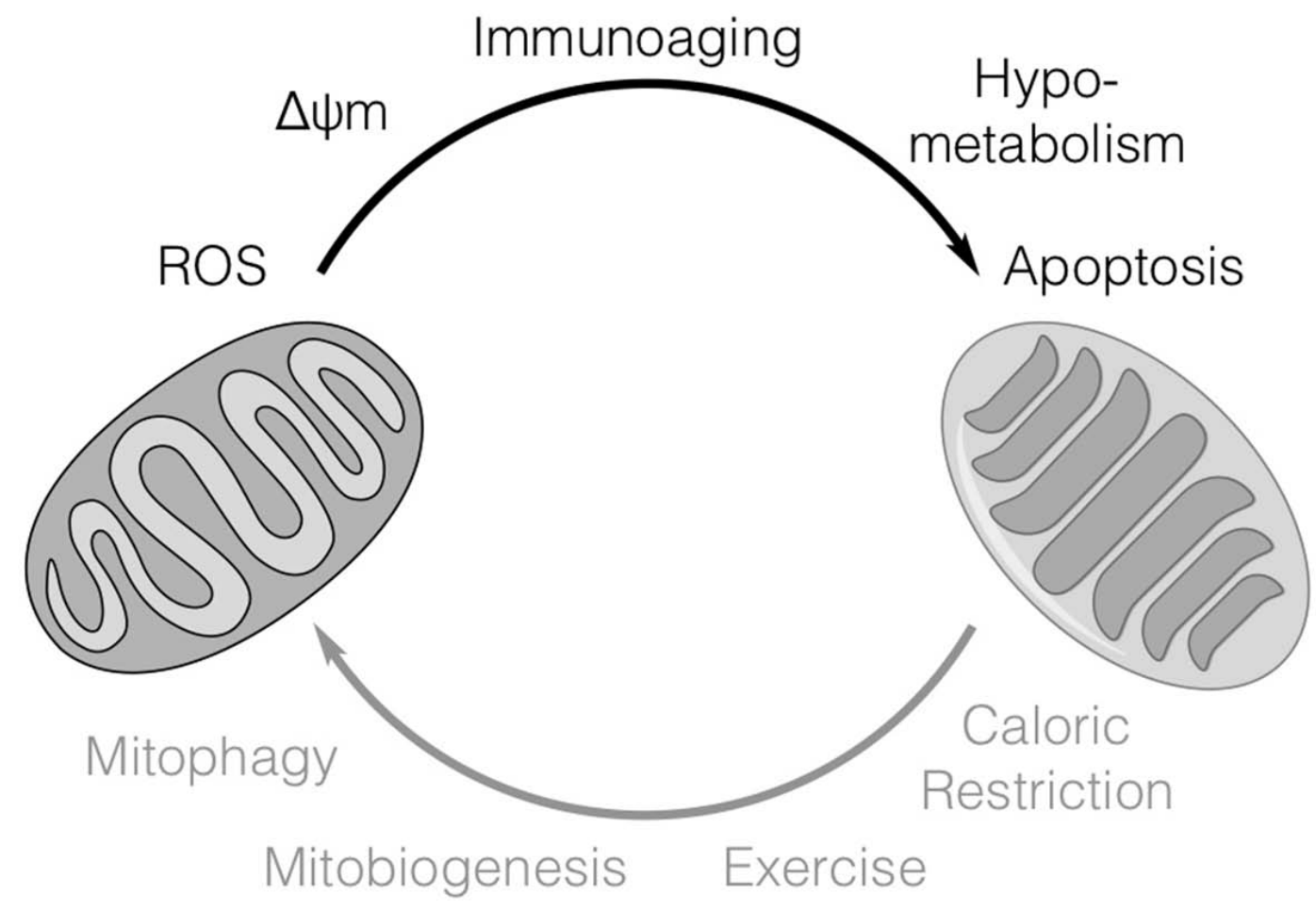

Figure 1. Factors regulating mitochondrial function in AD. In AD, neuronal injury, inflammation and aging may impair mitochondrial function by inducing fission, increasing $\Delta \psi \mathrm{m}$ and ROS production leading to decreased ATP production. Mitochondrial function may be improved by enhancing mitochondrial biogenesis through caloric restriction and exercise. Damaged and dysfunctional mitochondria can be selectively eliminated by mitophagy.

\section{Immunoaging and Mitochondrial Function}

Immune function is compromised during the course of aging as well as in AD. Investigations of changes in adaptive immune function associated with aging indicate disturbances of T- and B-cell homeostasis and activation as well as that of marcophages [194, 195]. Large scale (BLSA and MESA) transcriptomic studies of CD4+ T- cells and CD14+ monocytes from aged individuals show mitochondrial pathways, particularly OxPhos, as the most down-regulated (FDR <0.001) [196, 197]. The loss in OxPhos expression is significant as mitochondrial oxidative metabolism plays a critical regulatory role in immune function. Mitochondria serve as the scaffold for NLRP3 inflammasome formation, where mitochondrial ROS and oxidative metabolism regulate caspase-1 
activation, the critical step in maturation of Il-1beta and Il-18. Mitochondrial oxidative metabolism regulates macrophage polarization, T-cell activation, differentiation and memory cell formation (for review see Weinberg et al., 2015 [198]). Thus, mitochondria not only sustain immune cell phenotypes but also are necessary for establishing immune cell phenotype and function. In a pro-inflammatory state this is accomplished by mitochondria shifting from producing ATP via oxidative metabolism to producing building blocks for macromolecule synthesis via anapleurosis and glutaminolysis. The shift from catabolism to anabolism is critical to affect cell expansion, production of inflammatory mediators and immune cell fate commitments. This may explain why the increase in serum pro-inflammatory cytokines occurs with age, giving rise to a chronic state of inflammation, termed inflammaging [199-201].

In $\mathrm{AD}$, immune dysfunction has been identified in $\mathrm{T}$ and B-cells, macrophages and microglia [202]. AD is associated with increased $\mathrm{T}$ cell infiltration, changes in immune populations associated with disease progression, reduction in $\mathrm{T}$ - and $\mathrm{B}$-cell numbers and reductions in CD4+CD25+ Tregs [203]. CD8+CD28- suppressor cells are also decreased in PBMCs from AD patients. These data suggest that the immunosuppressive capabilities in $\mathrm{AD}$ patients are diminished and could represent a deficit in the ability to control Teff responses. As such, increased activities of Th17, levels of IL-21, IL-6, and IL-23, and the Th17-associated transcription factor ROR $\gamma$, were increased among lymphocytes in AD patients [204]. This suggests $\mathrm{AD}$ specific overactivity of Th17 T-cell function and underactivity of Teff function. Given that Th17 Tcells primarily mobilize glycolysis and suppress OxPhos whereas Tregs and memory $\mathrm{T}$ cells oxidize fatty acids via mitochondrial oxidation, supports the concept that mitochondrial dysfunction fuels AD immune dysfunction [205].

\section{Conclusion}

Mitochondrial function is deregulated in $\mathrm{AD}$ and there is growing interest in understanding how altered mitochondrial function may be targeted to inhibit neurodegeneration. Proper modulation of mitochondrial turnover overall to eliminate dysfunctional mitochondria while maintaining efficient functional mitochondrial mass in response to stresses, including hypoxia and nutrient starvation may be relevant in delaying or managing the degenerative process in aging and AD. By preventing the generation of excessive ROS and conserving valuable nutrients neuronal survival may be promoted under conditions of energetic stress (Figure 1).

\section{References}

[1] Swerdlow RH, Burns JM, Khan SM (2014). The Alzheimer's disease mitochondrial cascade hypothesis: progress and perspectives. Biochim Biophys Acta, 1842:1219-1231

[2] Fukui H, Moraes CT (2008). The mitochondrial impairment, oxidative stress and neurodegeneration connection: reality or just an attractive hypothesis? Trends Neurosci, 31:251-256

[3] Picone P, Nuzzo D, Caruana L, Scafidi V, Di Carlo M (2014). Mitochondrial Dysfunction: Different Routes to Alzheimer's Disease Therapy. Oxidative Medicine and Cellular Longevity. Oxid Med Cell Longev, 2014:780179.

[4] Scarpulla RC (2008). Transcriptional paradigms in mammalian mitochondrial biogenesis and function. . Physiol Rev, 88: 611-638.

[5] Mosconi L, Brys M, Switalski R, Mistur R, Glodzik L, Pirraglia E, et al. (2007). Maternal family history of Alzheimer's disease predisposes to reduced brain glucose metabolism. Proc Natl Acad Sci U S A, 104: 19067-19072.

[6] Murray J, Tsui WH, Li Y, McHugh P, Williams S, Cummings M, et al. (2014). FDG and Amyloid PET in Cognitively Normal Individuals at Risk for Late-Onset Alzheimer's Disease. Adv J Mol Imaging, 4: 15-26.

[7] Hirai K, Aliev G, Nunomura A, Fujioka H, Russell RL, Atwood CS, et al. (2001). Mitochondrial abnormalities in Alzheimer's disease. J Neurosci, 21: 3017-3023

[8] Moreira PI, Siedlak SL, Wang X, Santos MS, Oliveira CR, Tabaton M, et al. (2007). Increased autophagic degradation of mitochondria in Alzheimer disease. Autophagy, 3: 614-615.

[9] Parker WDJ, Parks JK (1995). Cytochrome c oxidase in Alzheimer's disease brain: purification and characterization. Neurology, 45: 482- 486

[10] Gibson GE, Sheu KF, Blass JP (1998). Abnormalities of mitochondrial enzymes in Alzheimer disease. J NeuralTransm, 105: 855-870.

[11] Maurer I, Zierz S, Moller HJ (2000). A selective defect of cytochrome $\mathrm{c}$ oxidase is present in brain of Alzheimer disease patients. Neurobiol Aging, 21: 455462

[12] Wang X, Su B, Siedlak SL, Moreira PI, Fujioka H, Wang Y, et al. (2008). Amyloid-beta overproduction causes abnormal mitochondrial dynamics via differential modulation of mitochondrial fission/fusion proteins. Proc Natl Acad Sci USA, 105: 19318-19323.

[13] Calkins MJ, Manczak M, Mao P, Shirendeb U, Reddy $\mathrm{PH}$ (2011). Impaired mitochondrial biogenesis, defective axonal transport of mitochondria, abnormal mitochondrial dynamics and synaptic degeneration in a mouse model of Alzheimer's disease. Hum Mol Genet, 20: 4515- 4529.

[14] Manczak M, Calkins MJ, Reddy PH (2011). Impaired mitochondrial dynamics and abnormal interaction of amyloid beta with mitochondrial protein Drp1 in neurons from patients with Alzheimer's disease: impli- 
cations for neuronal damage. Hum Mol Genet, 20: 2495-2509.

[15] Keller JN, Pang Z, Geddes JW, Begley JG, Germeyer A, Waeg G, et al. (1997). Impairment of glucose and glutamate transport and induction of mitochondrial oxidative stress and dysfunction in synaptosomes by amyloid beta-peptide: role of the lipid peroxidation product 4-hydroxynonenal. J Neurochem, 69: 273-284

[16] Abramov AY, Canevari L, Duchen MR (2004). Betaamyloid peptides induce mitochondrial dysfunction and oxidative stress in astrocytes and death of neurons through activation of NADPH oxidase. J Neurosci, 24: 565-575

[17] Manczak M, Anekonda TS, Henson E, Park BS, Quinn J, Reddy PH (2006). Mitochondria are a direct site of A beta accumulation in Alzheimer's disease neurons: implications for free radical generation and oxidative damage in disease progression. Hum Mol Genet, 15: 1437-1449

[18] Mattson MP, Partin J, Begley JG (1998). Amyloid betapeptide induces apoptosis-related events in synapses and dendrites. Brain Res, 807: 167- 176.

[19] Lustbader JW, Cirilli M, Lin C, Xu HW, Takuma K, Wang N, et al. (2004). ABAD directly links Abeta to mitochondrial toxicity in Alzheimer's disease. Science, 304: $448-452$

[20] Reddy PH (2008). Mitochondrial medicine for aging and neurodegenerative diseases. Neuromolecular Med, 10: 291-315

[21] Calkins MJ, Manczak M, Reddy PH (2012). Mitochondria-targeted antiox- idant SS31 prevents amyloid beta-induced mitochondrial abnormalities and synaptic degeneration in Alzheimer's disease. Pharmaceuticals, 5:1103-1119.

[22] Eckert GP, Renner K, Eckert SH, Eckmann J, Hagl S, Abdel-Kader RM, et al. (2012). Mitochondrial dysfunction a pharmacological target in Alzheimer's disease. Mol Neurobiol, 46: 136-150

[23] Reddy PH, Tripathi R, Troung Q, Tirumala K, Reddy TP, Anekonda V, et al. (2012). Abnormal mitochondrial dynamics and synaptic degeneration as early events in Alzheimer's disease: implications to mitochondria-targeted antioxidant therapeutics. Biochim Biophys Acta, 1822: 639 - 649

[24] Ryan MT, Hoogenraad NJ (2007). Mitochondrialnuclear communications. Annu Rev Biochem, 76: 701722.

[25] Liu X, Hajnóczky G (2011). Altered fusion dynamics underlie unique morphological changes in mitochondria during hypoxia-reoxygenation stress. Cell Death Differ, 18: 1561-1572

[26] Chan DC (2007). Mitochondrial dynamics in disease. N Engl J Med, 356: 1707 - 1709

[27] Medeiros DM (2008). Assessing mitochondria biogenesis. Methods, 46: 288-294

[28] Onyango IG, Lu J, Rodova M, Lezi E, Crafter AB, Swerdlow RH (2010). Regulation of neuron mitochondrial biogenesis and relevance to brain health. Biochim Biophys Acta, 1802: 228-234.
[29] Yin W, Signore AP, Iwai M, Cao G, Gao Y, Chen J (2008). Rapidly increased neuronal mitochondrial biogenesis after hypoxic-ischemic brain injury. . Stroke, 39:3057-3063

[30] Medeiros DM (2008). Assessing mitochondria biogenesis. Methods, 46: 288-294

[31] Kelly DP, Scarpulla RC (2004). Transcriptional regulatory circuits controlling mitochondrial biogenesis and function. Genes Dev, 18: 357-368

[32] Canto C, Auwerx J (2011). NAD+ as a signaling molecule modulating metabolism. Cold Spring Harb Symp Quant Biol, 76: 291-298.

[33] Gleyzer N, Vercauteren K, Scarpulla RC (2005). Control of Mitochondrial Transcription Specificity Factors (TFB1M and TFB2M) by Nuclear Respiratory Factors (NRF-1 and NRF-2) and PGC-1 Family Coactivators. Molecular and Cellular Biology, 25: 1354-1366

[34] Bruni F, Polosa PL, Gadaleta MN, Cantatore P, Roberti M (2010). Nuclear Respiratory Factor 2 Induces the Expression of Many but Not All Human Proteins Acting in Mitochondrial DNA Transcription and Replication. J Bio Chem, 285: 3939-3948.

[35] Twig G, Elorza A, Molina AJ, Mohamed H, Wikstrom JD, Walzer G, et al. (2008). Fission and selective fusion govern mitochondrial segregation and elimination by autophagy. Embo J, 27: 433-446

[36] Youle RJ, Narendra DP (2011). Mechanisms of mitophagy. Nat Rev Mol Biol, 12: 9-14

[37] Qin W, Haroutunian V, Katsel P, Cardozo CP, Ho L, Buxbaum JD, et al. (2009). PGC-1 $\alpha$ expression decreases in the Alzheimer disease brain as a function of dementia. Arch Neurol, 66: 352-361.

[38] Hirai K, Aliev G, Nunomura A, Fujioka H, Russell RL, Atwood CS, et al. (2001). Mitochondrial abnormalities in Alzheimer's disease. J Neurosci, 21: 3017-3023

[39] Sheng B, Wang X, Su B, Lee HG, Casadesus G, Perry $\mathrm{G}$, et al. (2012). Impaired mitochondrial biogenesis contributes to mitochondrial dysfunction in Alzheimer's disease. J Neurochem, 120: 419-429.

[40] Dominy JE, Lee YS, Gerhart-Hines Z, Puigserver P (2010). Nutrient-dependent regulation of PGC-1a's acetylation state and metabolic function through the enzy- matic activities of Sirt1/GCN5. Biochim Biophys Acta, 1804: 1676-1683

[41] Rasbach KA, Schnellmann RG (2007). Signaling of mitochondrial biogenesis following oxidant injury. J Biol Chem, 282: 2355-2362.

[42] Rohas LM, St-Pierre J, Uldry M, Jager S, Handschin C, Spiegelman BM (2007). A fundamental system of cellular energy homeostasis regulated by PGC-1a. Proc Natl Acad Sci U S A, 104: 7933-7938.

[43] Bell EL, Guarente L (2011). The SirT3 divining rod points to oxidative stress. Mol Cell, 42: 561-568

[44] Shin JH, Ko HS, Kang HS, Lee YK, Lee YI, Pletinkova O (2011). PARIS (ZNF746) repression of PGC-1 $\alpha$ contributes to neurodegeneration in Parkinson's disease. Cell, 144: 689-702 
[45] Kim I, Rodriguez-Enriquez S, Lemasters JJ (2007). Selective degradation of mitochondria by mitophagy. Arch Biochem. Biophys, 462: 245-253

[46] Scherz-Shouval R, Elazar Z (2011). Regulation of autophagy by ROS: physiology and pathology. Trends Biochem Sci, 36: 30-38

[47] Narendra DP, Youle RJ (2011). Targeting mitochondrial dysfunction: role for PINK1 and Parkin in mitochondrial quality control. Antioxid. Redox Signal, 14: 1929-1938

[48] Narendra D, Kane LA, Hauser DN, Fearnley IM, Youle $\mathrm{RJ}$ (2010). p62/SQSTM1 is required for Parkin-induced mitochondrial clustering but not mitophagy; VDAC1 is dispensable for both. Autophagy, 6: 1090-1106

[49] Jin SM, Lazarou M, Wang C, Kane LA, Narendra DP, Youle RJ (2010). Mitochondrial membrane potential regulates PINK1 import and proteolytic destabilization by PARL. J Cell Biol, 191: 933-942

[50] Valente EM, Abou-Sleiman PM, Caputo V, Muqit MM, Harvey K, Gispert S, et al. (2004). Hereditary earlyonset Parkinson's disease caused by mutations in PINK1. Science, 304: 1158-1160

[51] Geisler S, Holmstrom KM, Skujat D, Fiesel FC, Rothfuss OC, Kahle PJ, et al. (2010). PINK1/Parkinmediated mitophagy is dependent on VDAC1 and p62/SQSTM1. Nat Cell Biol, 12: 119-131

[52] Pankiv S, Clausen TH, Lamark T, Brech A, Bruun JA, Outzen H, et al. (2007). p62/SQSTM1 binds directly to Atg8/LC3 to facilitate degradation of ubiquitinated protein aggregates by autophagy. J Biol Chem, 282: 24131-24145

[53] Liu L, Feng D, Chen G, Chen M, Zheng Q, Song P, et al. (2012). Mitochondrial outer-membrane protein FUNDC1 mediates hypoxia-induced mitophagy in mammalian cells. Nat Cell Biol, 14: 177-185

[54] Novak I, Kirkin V, McEwan DG, Zhang J, Wild P, Rozenknop A, et al. (2010). Nix is a selective autophagy receptor for mitochondrial clearance. EMBO Rep, 11: 45-51

[55] Ding WX, Yin XM (2012). Mitophagy, mechanisms, pathophysiological roles, and analysis. Biol Chem, 393: 547-564

[56] Fu M, St-Pierre P, Shankar J, Wang PT, Joshi B, Nabi IR (2013). Regulation of mitophagy by the Gp78 E3 ubiquitin ligase. Mol Biol Cell, 24: 1153-1162.

[57] Lokireddy S, Wijesoma IW, Teng S, Bonala S, Gluckman PD, McFarlane C, et al. (2012). The ubiquitin ligase Mul1 induces mitophagy in skeletal muscle in response to muscle-wasting stimuli. Cell Metab, 16: 613-624

[58] Ishii T, Itoh K, Takahashi S, Sato H, Yanagawa T, Katoh Y, et al. (2000). Transcription factor Nrf2 coordinately regulates a group of oxidative stressinducible genes in macrophages. J Biol Chem, 275: 16023-16029

[59] Jain A, Lamark T, Sjøttem E, Larsen KB, Awuh JA, Øvervatn A, et al. (2010). p62/SQSTM1 is a target gene for transcription factor NRF2 and creates a positive feedback loop by inducing antioxidant response element-driven gene transcription. J Biol Chem, 285: 22576-22591

[60] Cheng X, Siow RC, Mann GE (2011). Impaired redox signaling and antioxidant gene expression in endothelial cells in diabetes: a role for mitochondria and the nuclear factor-E2-related factor 2-Kelch-like ECHassociated protein 1 defense pathway. Antioxid Redox Signal, 14: 469-487

[61] Hayes JD, McMahon M, Chowdhry S, DinkovaKostova AT (2010). Cancer chemoprevention mechanisms mediated through the Keap1-Nrf2 pathway. Antioxid Redox Signal, 13: 1713-1748.

[62] Kensler TW, Wakabayashi N, Biswal S (2007). Cell survival responses to environmental stresses via the Keap1-Nrf2-ARE pathway. Annu Rev Pharmacol. Toxicol, 47: 89-116

[63] East DA, Fagiani F, Crosby J, Georgakopoulos ND, Bertrand H, M. S, et al. (2014). PMI: A $\Delta \Psi \mathrm{m}$ Independent Pharmacological Regulator of Mitophagy. Chemistry \& Biology, 21: 1585-1596

[64] Vives-Bauza C, Zhou C, Huang Y, Cui M, de Vries RL, Kim J (2010). PINK1- dependent recruitment of Parkin to mitochondria in mitophagy. Proc Natl Acad Sci U S A, 107: 378-383

[65] Wang X, Winter D, Ashrafi G, Schlehe J, Wong YL, Selkoe D (2011). PINK1 and Parkin target Miro for phosphorylation and degradation to arrest mitochondrial motility. Cell, 147: 893-906.

[66] Cho DH, Nakamura T, Fang J, Cieplak P, Godzik A, Gu Z, et al. (2009). S-nitrosylation of Drp1 mediates betaamyloid-related mitochondrial fission and neuronal injury. Science, 324: 102-105

[67] Lee JY, Koga H, Kawaguchi Y, Tang W, Wong E, Gao YS (2010). HDAC6 controls autophagosome maturation essential for ubiquitin-selective qualitycontrol autophagy. EMBO J, 29: 969-980

[68] Lee JY, Nagano Y, Taylor JP, Lim KL, Yao TP (2010). Disease-causing mutations in Parkin impair mitochondrial ubiquitination, aggregation, and HDAC6- dependent mitophagy. J Cell Biol, 189: 671679.

[69] de Castro IP, Martins LM, Tufi R (2010). Mitochondrial quality control and neurological disease: an emerging connection. Expert Rev Mol Med, 12: e12 Karbowski M, Neutzner A (2012). Neurodegeneration as a consequence of failed mitochondrial maintenance. Acta Neuropathol, 123: 157-171

[71] Horn SR, Thomenius MJ, Johnson ES, Freel CD, Wu JQ, Coloff JL (2011). Regulation of mitochondrial morphology by APC/CCdh1-mediated control of Drp1 stability. Mol Biol Cell, 22: 1207-1216

[72] Kashatus DF, Lim KH, Brady DC, Pershing NL, Cox AD, Counter CM (2011). RALA and RALBP1 regulate mitochondrial fission at mitosis. Nat Cell Biol, 13: 1108-1115

[73] Twig G, Hyde B, Shirihai OS (2008). Mitochondrial fusion, fission and autophagy as a quality control axis: the bioenergetic view. Biochim Biophys Acta, 1777: 1092-1097 
[74] Martinou JC, Youle RJ (2011). Mitochondria in apoptosis:Bcl-2 family members and mitochondrial dynamics. Dev Cell, 21: 92-101

[75] Autret A, Martin SJ (2009). Emerging role for members of the B1-2 family in mito- chondrial morphogenesis. Mol Cell, 36: 355-363

[76] Youle RJ, van der Bliek AM (2012). Mitochondrial fission, fusion and stress. Science, 337: 1062-1065.

[77] Palmer CS, Osellame LD, Laine D, Koutsopoulos OS, Frazier AE, Ryan MT (2011). MiD49 and MiD51, new components of the mitochondrial fission machinery. EMBO reports, 12: 565-573

[78] Bossy B, Petrilli A, Klinglmayr E, Chen J, Lütz-Meindl U, Knott AB, et al. (2010). S-Nitrosylation of DRP1 does not affect enzymatic activity and is not specific to Alzheimer's disease. Journal of Alzheimer's disease, 20: S513-526

[79] Nakamura T, Lipton SA (2011). Redox modulation by S-nitrosylation contributes to protein misfolding, mitochondrial dynamics, and neuronal synaptic damage in neurodegenerative diseases. Cell Death Differ, 18: 1478-1486.

[80] Sauvanet C, Duvezin-Caubet S, di Rago JP, Rojo M (2010). Energetic requirements and bioenergetic modulation of mitochondrial morphology and dynamics. Semin Cell Dev Biol, 21: 558-565

[81] Montessuit S, Somasekharan SP, Terrones O, LuckenArdjomande S, Herzig S, Schwarzenbacher R (2010). Membrane remodeling induced by the dynamin- related protein Drp1 stimulates Bax oligomerization. Cell, 142: 889-901

[82] Li H, Chen Y, Jones AF, Sanger RH, Collis LP, Flannery R (2008). Bcl-xL induces Drp1-dependent synapse formation in cultured hippocampal neurons. Proc Natl Acad Sci U S A, 105: 2169-2174

[83] Wang H, Lim PJ, Karbowski M, Monteiro MJ (2008). Effects of overexpression of Huntingtin proteins on mitochondrial integrity. Hum Mol Genet, 18: 737-752

[84] Hamblet NS, Ragland B, Ali M, Conyers B, Castora FJ (2006). Mutations in mitochondrial-encoded cytochrome c oxidase subunits I, II, and III genes detected in Alzheimer's disease using single-strand conformation polymorphism. Electrophoresis, 27: 398408

[85] Chandrasekaran K, Hatanpää K, Brady DR, Rapoport SI (1996). Evidence for physiological down-regulation of brain oxidative phosphorylation in Alzheimer's disease. Exp Neurol, 142: 80-88

[86] Cassidy-Stone A, Chipuk JE, Ingerman E, Song C, Yoo C, Kuwana T, et al. (2008). Chemical inhibition of the mitochondrial division dynamin reveals its role in Bax/Bak-dependent mitochondrial outer membrane permeabilization. Dev Cell, 14: 193-204.

[87] Brooks C, Wei Q, Cho SG, Dong Z (2009). Regulation of mitochondrial dynamics in acute kidney injury in cell culture and rodent models. J Clin Invest, 119: 12751285.

[88] Ong SB, Subrayan S, Lim SY, Yellon DM, Davidson SM, Hausenloy DJ (2010). Inhibiting mitochondrial fission protects the heart against ischemia/reperfusion injury. Circulation, 121: 2012-2022

[89] Park SW, Kim KY, Lindsey JD, Dai Y, Heo H, Nguyen DH, et al. (2011). Selective Inhibitor of Drp1, Mdivi-1, Increases Retinal Ganglion Cell Survival in Acute Ischemic Mouse Retina. Invest Ophthalmol Vis Sci, 52: 2837-2843.

[90] Cui M, Tang X, Christian WV, Yoon Y, Tieu K (2010). Perturbations in mitochondrial dynamics induced by human mutant PINK1 can be rescued by the mitochondrial division inhibitor mdivi-1. J Biol Chem, 285: 11740-11752

[91] Madamanchi NR, Runge MS (2007). Mitochondrial dysfunction in atherosclerosis. Circ Res, 100: 460-473.

[92] Ohashi S, Nishio A, Nakamura H, Kido M, Ueno S, Uza $\mathrm{N}$, et al. (2006). Protective roles of redox-active protein thioredoxin-1 for severe acute pancreatitis. Am J Physiol Gastrointest Liver Physiol, 290: G772-781

[93] Valko M, Leibfritz D, Moncol J, Cronin MT, Mazur M, Telser J (2007). Free radicals and antioxidants in normal physiological functions and human disease Int $\mathbf{J}$ Biochem Cell Biol, 39: 44-84.

[94] Ramsden DB, Ho PW-L, Ho JW-M, al e (2012). Human neuronal uncoupling proteins 4 and 5 (UCP4 and UCP5): structural properties, regulation, and physiological role in protection against oxidative stress and mitochondrial dysfunction. Brain and Behavior, 2: 468-478.

[95] (2001). $\Delta \phi \mathrm{m}$ dependent and independent production of reactive oxygen species by rat brain mitochondria. $\mathbf{J}$ Neurochem, 79: 266-277

[96] Brennan JP, Southworth R, Medina RA, Davidson SM, Duchen MR, Shattock MJ (2006). "Mitochondrial uncoupling, with low concentration FCCP, induces ROS-dependent cardioprotection independent of KATP channel activation." Cardiovas Res, 72: 313-321.

[97] Skulachev VP (1998). Uncoupling: new approaches to an old problem of bioenergetics. Biochim Biophys Acta, 1363: 100-124

[98] Korshunov SS, Skulachev VP, Starkov AA (1997). High protonic potential actuates a mechanism of production of reactive oxygen species in mitochondria. FEBS Lett, 416: 15-18.

[99] Brookes PS (2005). Mitochondrial H(+) leak and ROS generation: an odd couple. . Free Radic Biol Med, 38: 12-23

[100] Brand MD, Buckingham JA, Esteves T (2004). Mitochondrial superoxide and aging: uncouplingprotein activity and superoxide production. Biochem Soc Symp, 203-213

[101] Hauptmann S, Scherping I, Drose S, Brandt U, Schulz KL, Jendrach M, et al. (2009). Mitochondrial dysfunction: an early event in Alzheimer pathology accumulates with age in AD transgenic mice. Neurobiol aging, 30: 1574-1586

[102] Reddy PH (2009). Amyloid beta, mitochondrial structural and functional dynamics in Alzheimer's disease. Exp Neurol, 2, 218: 286-292 
[103] Xie H, Guan J, Borrelli LA, Xu J, Serrano-Pozo A, Bacskai BJ (2013). Mitochondrial Alterations near Amyloid Plaques in an Alzheimer's Disease Mouse Model. J Neurosci, 33: 17042-17051

[104] Deshpande A, Mina E, Glabe C, Busciglio J (2006). Different conformations of amyloid beta induce neurotoxicity by distinct mechanisms in human cortical neurons. J Neurosci, 26: 6011-6018

[105] Cabezas-Opazo FA, Vergara-Pulgar K, Pérez MJ, Jara C, Osorio-Fuentealba C, Quintanilla RA (2015). Mitochondrial Dysfunction Contributes to the Pathogenesis of Alzheimer's Disease. Oxid Med Cell Longev, 2015:509654

[106] Aon MA, Cortassa S, O'Rourke B (2010). Redoxoptimized ROS balance: A unifying hypothesis. Biochim Biophys Acta, 1797: 865-877

[107] Echtay KS, Roussel D, St-Pierre J, Jekabsons MB, Cadenas S, Stuart J, et al. (2002). Superoxide activates mitochondrial uncoupling proteins. Nature, 415: 96-99

[108] Murphy MP, Echtay KS, Blaikie FH, Asin-Cayuela J, Cocheme HM, Gree K, et al. (2003). Superoxide activates uncoupling proteins by generating carboncentered radicals and initiating lipid peroxidation. $\mathbf{J}$ Biol Chem, 278: 48534-48545

[109] Brookes PS, Land JM, Clark JB, Heales SJ (1998). Peroxynitrite and brain mitochondria: evidence for increased proton leak. J Neurochem, 70: 2195-2202.

[110] Miwa S, Brand MD (2003). Mitochondrial matrix reactive oxygen species production is very sensitive to mild uncoupling. Biochem Soc Trans, 311: 1300-1301.

[111] Jezek P, Engstova H, Zackova M (1998). Fatty acid cycling mechanism and mitochondrial uncoupling proteins. Biochim Biophys Acta, 1365: 319-327

[112] Skulachev VP (1991). Fatty acid circuit as a physiological mechanism of uncoupling of oxidative phosphorylation. FEBS Lett, 294: 158-162

[113] Pecqueur C, Alves-Guerra MC, Gelly C (2001). Uncoupling protein 2 , in vivo distribution, induction upon oxidative stress, and evidence for translational regulation. J Biol Chem, 276: 8705-8712

[114] Ricquier D, Bouillaud F (2000). The uncoupling protein homologues: UCP1, UCP2, UCP3, StUCP and AtUCP. Biochem J, 345: 161-179

[115] Andreyev A, Bondareva TO, Dedukhova VI (1988). Carboxyatractylate inhibits the uncoupling effect of free fatty acids. FEBS Lett, 226: 265-269

[116] Hoerter J, Gonzalez-Barroso MD, Couplan E (2004). Mitochondrial uncoupling protein 1 expressed in the heart of transgenic mice protects against ischemicreperfusion damage. Circulation, 110: 528-533

[117] McLeod CJ, Aziz A, Hoyt RFJ, McCoy JPJ, Sack MN (2005). Uncoupling proteins 2 and 3 function in concert to augment tolerance to cardiac ischemia. J Biol Chem, 280: 33470-33476

[118] Hamanaka RB, Chandel NS (2010). Mitochondrial reactive oxygen species regulate cellular signaling and dictate biological outcomes. Trends Biochem Sci, 35: 505-513
[119] Mammucari C, Rizzuto R (2010). Signaling pathways in mitochondrial dysfunction and aging. Mech Ageing Dev, 131: 536-543

[120] Ristow M, Zarse K, Oberbach A, et al. (2009). Antioxidants prevent health-promoting effects of physical exercise in humans. Proc Natl Acad Sci U S A, 106: 8665-8670

[121] Ristow M, Zarse K (2010). How increased oxidative stress promotes longevity and metabolic health: the concept of mitochondrial hormesis (mitohormesis). Exp Gerontol, 45: 410-418

[122] Kenyon CJ (2010). The genetics of ageing. Nature, 464: 504-512

[123] Schulz TJ, et al (2007). Glucose restriction extends Caenorhabditis elegans life span by inducing mitochondrial respiration and increasing oxidative stress. Cell Metab, 6: 280-293

[124] Yun J, Finkel T (2014). Mitohormesis. Cell Metab, 19: 757-766

[125] Feng J, Bussière F, Hekimi S (2001). Mitochondrial electron transport is a key determinant of life span inCaenorhabditis elegans. Dev Cell, 1: 633-644

[126] Copeland JM, Cho J, Lo TJ, Hur J, Bahadorani S, Arabyan T, et al. (2009). Extension of Drosophila life span by RNAi of the mitochondrial respiratory chain. Curr Biol, 19: 1591-1598

[127] Dell'agnello C, Leo S, Agostino A, Szabadkai G, Tiveron C, Zulian A, et al. (2007). Increased longevity and refractoriness to $\mathrm{Ca}(2+)$-dependent neurodegeneration inSurf1 knockout mice. Hum Mol Genet, 16: 431-444

[128] Durieux J, Wolff S, Dillin A (2011). The cell-nonautonomous nature of electron transport chainmediated longevity. Cell, 144: 79-91

[129] Bennett CF, Kaeberlein M (2014). The mitochondrial unfolded protein response and increased longevity: cause, consequence, or correlation? Exp Gerontol, 56: $42-46$

[130] Bennett CF, Vander Wende H, Simko M, Klum S, Barfield S, Choi H, et al. (2014). Activation of the mitochondrial unfolded protein response does not predict longevity in Caenorhabditis elegans. Nat Commun, 5: 3483

[131] Artal-Sanz M, Tavernarakis N (2009). Prohibitin and mitochondrial biology. Endocrinol Metab, 20: 394-401

[132] Dirks AJ, Leeuwenburgh C (2006). Caloric restriction in humans: potential pitfalls and health concerns. Mech Ageing Dev, 127: 1-7

[133] Sohal RS, Ku HH, Agarwal S, Forster MJ, Lal H (1994). Oxidative damage, mitochondrial oxidant generation and antioxidant defenses during aging and in response to food restriction in the mouse. Mech Ageing Dev, 74: 121-133

[134] Melov S, Hinerfeld D, Esposito L, Wallace DC (1997). Multi-organ characterization of mitochondrial genomic rearrangements in ad libitum and caloric restricted mice show striking somatic mitochondrial DNA rearrangements with age. Nucleic Acids Research, 25: 974-982. 
[135] Mattson MP (2012). Energy Intake and Exercise as Determinants of Brain Health and Vulnerability to Injury and Disease. Cell metabolism, 16: 706-722.

[136] Gillette - Guyonnet S, Secher M, Vellas B (2013). Nutrition and neurodegeneration: epidemiological evidence and challenges for future research. Br J Clin Pharmacol, 75: 738-755.

[137] Fulton D, Gratton JP, McCabe TJ (1999). Regulation of endothelium-derived nitric oxide production by the protein kinase Akt. Nature, 399: 597-601

[138] Chen H, Montagnani M, Funahashi T, Shimomura I, Quon MJ (2003). Adiponectin stimulates production of nitric oxide in vascular endothelial cells. J Biol Chem, 278: 45021-45026.

[139] Nisoli E, Tonello C, Cardile A (2005). Calorie restriction promotes mitochondrial biogenesis by inducing the expression of eNOS. Science, 310: 314317

[140] Rashid G, Bernheim J, Green J, Benchetrit S (2007). Parathyroid hormone stimulates the endothelial nitric oxide synthase through protein kinase $\mathrm{A}$ and $\mathrm{C}$ pathways. Nephrol Dial Transplant., 22: 2831-2837.

[141] Ritchie SA, Kohlhaas CF, Boyd AR, Yalla KC, Walsh K, Connell JM, et al. (2010). Insulin-stimulated phosphorylation of endothelial nitric oxide synthase at serine-615 contributes to nitric oxide synthesis. Biochem J, 426: 85-90

[142] Cerqueiram FM, Laurindo FR, Kowaltowski AJ (2011). Mild mitochondrial uncoupling and calorie restriction increase fasting eNOS, akt and mitochondrial biogenesis. PLoS One, 6:e18433

[143] Nisoli E, Clementi E, Paolucci C (2003). Mitochondrial biogenesis in mammals: the role of endogenous nitric oxide. Science, 299: 896-899

[144] Nisoli E, Falcone S, Tonello C (2004). Mitochondrial biogenesis by NO yields functionally active mitochondria in mammals. Proc Natl Acad Sci U S A, 101: $16507-16512$

[145] Hu Z, Chen J, Wei Q, Xia Y (2008). Bidirectional actions of hydrogen peroxide on endothelial nitricoxide synthase phosphorylation and function: cocommitment and interplay of Akt and AMPK. J Biol Chem, 283: 25256-25263

[146] Zhou X, Bohlen HG, Unthank JL, S.J. M (2009). Abnormal nitric oxide production in aged rat mesenteric arteries is mediated by $\mathrm{NAD}(\mathrm{P}) \mathrm{H}$ oxidasederived peroxide. Am J Physiol Heart Circ Physiol, 297: H2227-2233.

[147] Civitarese AE, Carling S, Heilbronn L (2007). Calorie restriction increases muscle mitochondrial biogenesis in healthy humans. PLoS Med, 4:e76

[148] Lee IH, Cao L, Mostoslavsky R (2008). A role for the NAD-dependent deacetylase Sirt1 in the regulation of autophagy. Proc Natl Acad Sci U S A, 105: 3374-3379.

[149] Wohlgemuth SE, Julian D, Akin DE, al. e (2007). Autophagy in the heart and liver during normal aging and calorie restriction. Rejuvenation Res, 10: 281-292.

[150] Donati A, Cavallini G, Paradiso C (2001). Age-related changes in the autophagic proteolysis of rat isolated liver cells: effects of antiaging dietary restrictions. J Gerontol A Biol Sci Med Sci, 56: B375-383.

[151] Bergamini E, Cavallini G, Donati A, Gori Z (2007). The role of autophagy in aging: its essential part in the antiaging mechanism of caloric restriction. Ann N Y Acad Sci, 11145: 69-78

[152] Simonsen A, Cumming RC, Brech A, al. e (2008). Promoting basal levels of autophagy in the nervous system enhances longevity and oxidant resistance in adult Drosophila. . Autophagy, 4: 176- 184.

[153] Steiner JL, Murphy EA, McClellan JL, Carmichael MD, Davis JM (2011). Exercise training increases mitochondrial biogenesis in the brain. J Appl Physiol, 111: 1066-1071

[154] Little JP, Safdar A, Wilkin GP, Tarnopolsky MA, Gibala MJ (2010). A practical model of low-volume high-intensity interval training induces mitochondrial biogenesis in human skeletal muscle: potential mechanisms. J Physiol, 588: 1011-1022

[155] Little JP, Safdar A, Cermak N, Tarnopolsky MA, Gibala MJ (2010). Acute endurance exercise increases the nuclear abundance of PGC-1alpha in trained human skeletal muscle. Am J Physiol Regul Integr Comp Physiol, 298: R912-917

[156] Safdar A, Little JP, Stokl AJ, al. e (2011). Exercise Increases Mitochondrial PGC-1 1 alpha $\}$ Content and Promotes Nuclear-Mitochondrial Cross-talk to Coordinate Mitochondrial Biogenesis. J Biol Chem, 286: 10605-10617

[157] Menshikova EV, Ritov VB, Fairfull L (2006). Effects of exercise on mitochondrial content and function in aging human skeletal muscle. J Gerontol A Biol Sci Med Sci, 61: 534-540

[158] Vina J, Gomez-Cabrera MC, Borras C, Froio T, Sanchis-Gomar F, Martinez-Bello VE, et al. (2009). Mitochondrial biogenesis in exercise and in ageing. Adv Drug Deliv Rev, 61: 1369-1374

[159] Short KR, Vittone JL, Bigelow ML, Proctor DN, Rizza RA, Coenen-Schimke JM, et al. (2003). Impact of aerobic exercise training on age-related changes in insulin sensitivity and muscle oxidative capacity. Diabetes, 52: 1888-1896

[160] Ghosh S, Lertwattanarak R, Lefort N (2011). Reduction in reactive oxygen species production by mitochondria from elderly subjects with normal and impaired glucose tolerance. Diabetes, 60: 2051-2060.

[161] Psilander N, Frank P, Flockhart M, Sahlin K (2013). Exercise with low glycogen increases PGC- $1 \alpha$ gene expression in human skeletal muscle. European Journal of Applied Physiology, 113: 951-963

[162] Lefevre M, Redman LM, Heilbronn LK, Smith JV, Martin CK, Rood JC, et al. (2009). Caloric restriction alone and with exercise improves CVD risk in healthy non-obese individuals. Atherosclerosis, 203: 206-213.

[163] Gomez-Cabrera MC, Domenech E, M. R (2008). Oral administration of vitamin $\mathrm{C}$ decreases muscle mitochondrial biogenesis and hampers training-induced adaptations in endurance performance. Am J Clin Nutr, 87: $142-149$. 
[164] Sena LA, Chandel NS (2012). Physiological roles of mitochondrial reactive oxygen species. Mol Cell, 48: 158-167

[165] Havens CG, Ho H, Yoshioka N, Dowdy SF (2006). Regulation of late G1/S phase tran- sition and APCCdh1 by reactive oxygen. Mol Cell Biol, 26: 47014711

[166] Balaban RS, Nemoto S, Finkel T (2005). Mitochondria, oxidants and aging. Cell, 120: 483-495

[167] Tormos KV, Anso E, Hamanaka RB, Eisenbart J, Joseph J, Kalyanaraman B, et al. (2011). Mitochondrial complex III ROS regulate adipocyte differentiation. Cell Metab, 14: 537-544

[168] Fu Z, Tindall DJ (2008). FOXOs, cancer and regulation of apoptosis. Oncogene, 27: 2312-2319.

[169] Kops GJ, Dansen TB, Polderman E, Saarloos I, Wirtz KWA, PJC (2002). Forkhead transcription factor FOXO3a protects quiescent cells from oxidative stress. Nature, 419: 316-321

[170] Mihaylova MM, Shaw RJ (2011). The AMPK signaling pathway coordinates cell growth, autophagy and metabolism. Nat Rev Cell Biol, 13: 1016-1023

[171] Alto NM, Soderling J, Scott JD (2002). Rab32 is an Akinase anchoring protein and participates in mitochondrial dynamics. J Cell Sci, 158: 659-6810

[172] Bera AK, Ghosh S, Das S (1995). Mitochondrial VDAC can be phosphorylated by cyclic AMPdependent protein kinase. Biochem Biophys Res Commun, 209: 213-217

[173] Das S, Wong R, Rajapakse N, Murphy E, Steenbergen C (2008). Glycogen synthase kinase 3 inhibition slows mitochondrial adenine nucleotide transport and regulates voltage-dependent anion channel phosphorylation. Circ Res, 103: 983-9110.

[174] Juhaszova M, Zorov DB, Kim SH, Pepe S, Fu Q, Fishbein KW (2004). Glycogen synthase kinase-3beta mediates convergence of protection signaling to inhibit the mitochondrial permeability transition pore. J Clin Invest, 113: 1535-4910

[175] Kumar S, Bharti A, Mishra NC, Raina D, Kharbanda S, Saxena S (2001). Targeting of the c-Abl tyrosine kinase to mitochondria in the necrotic cell death response to oxidative stress. J Biol Chem, 276: 17281-17510

[176] Majumder PK, Mishra NC, Sun X, Bharti A, Kharbanda S, Saxena S (2001). Targeting of protein kinase C delta to mitochondria in the oxidative stress response. Cell Growth Differ, 12: 465-470

[177] Robey RB, Hay N (2009). Is Akt the "Warburg kinase"? - Akt energy metabolism interactions and oncogenesis. Semin Cancer Biol, 19: 25-31

[178] Maurer U, Chavret C, Wagman AS, Dejardin E, Green DR (2006). Glycogen synthase kinase-3 regulates mitochondrial outer membrane permeabilization and apoptosis by destabilization of MCL-1. Mol Cell, 21: 749-6010

[179] Martel C, Allouche M, Esposti DD, Fanelli E, Boursier C, Henry C (2013). Glycogen synthase kinase 3mediated voltage-dependent anion channel phosphorylation controls outer mitochondrial membrane permeability during lipid accumulation. Hepatology, 57: 93-102

[180] Diehl JA, Cheng M, Roussel MF, Sherr CJ (1998). Glycogen synthase kinase-3 beta regulates cyclin D1 proteolysis and subcellular localisation. Genes Dev, 12: 3499-3511

[181] Rubinfeld B, Albert I, Porfiri E, Fiol C, Munemitsu S, Polakis P (1996). Binding of GSK3B to the APC-bcatenin complex and regulation of complex assembly. Science, 272: 1023-1610.

[182] Yeh E, Cunningham M, Arnold H, Chasse D, Monteith T, Ivaldi G, et al. (2004). A signalling pathway controlling c-Myc degradation that impacts oncogenic transformation of human cells. Nat Cell Biol, 6: 308318

[183] Kim J, Kundu M, Viollet B, Guan KL (2011). AMPK and mTOR regulate autophagy through direct phosphorylation of Ulk1. Nat Cell Biol, 13: 132-141

[184] Carlucci A, Adornetto A, Scorziello A, Viggiano D, Foca M, Cuomo O (2008). Proteolysis of AKAP121 regulates mitochondrial activity during cellular hypoxia and brain ischaemia. EMBO J, 27: 1073-8410.

[185] Livigni A, Scorziello A, Agnese S, Adornetto A, Carlucci A, Garbi C (2006). Mitochondrial AKAP121 links cAMP and src signaling to oxidative metabolism. Mol Biol Cell, 17: 263-7110.

[186] Miyazaki T, Neff L, Tanaka S, Horne WC, R. B (2003). Regulation of cytochrome c oxidase activity by c-Src in osteoclasts. J Cell Biol, 160: 709-718

[187] Tibaldi E, Brunati AM, Massimino ML, Stringaro A, Colone M, Agostinelli E, et al. (2008). Src-Tyrosine kinases are major agents in mitochondrial tyrosine phosphorylation. J Cell Biochem, 104: 840-910

[188] Hardie DG (2011). AMP-activated protein kinase - an energy sensor that regulates all aspects of cell function. Genes Dev, 25: 1895-1908

[189] Jäger S, Handschin C, St-Pierre J, B.M. S (2007). AMPactivated protein kinase (AMPK) action in skeletal muscle via direct phosphorylation of PGC-1 1alpha. Proc Natl Acad Sci U S A,104: 12017-12022.

[190] Zong H, Ren JM, Young LH, Pypaert M, Mu J, Birnbaum MJ, et al. (2002). AMP kinase is required for mitochondrial biogenesis in skeletal muscle in response to chronic energy deprivation. Proc Natl Acad Sci U S A, 99: 15983-15987

[191] Egan DF, Shackelford DB, Mihaylova MM, Gelino S, Kohnz RA, Mair W (2011). Phosphorylation of ULK1 (hATG1) by AMP-activated protein kinase connects energy sensing to mitophagy. Science, 331: 456-461

[192] Petersen AJ, Rimkus SA, Wassarman DA (2012). ATM kinase inhibition in glial cells activates the innate immune response and causes neurodegeneration in Drosophila. Proc Natl Acad Sci U S A, 109: E656-E664

[193] Valentin-Vega YA, MacLean KH, Tait-Mulder J, Milasta S, Steeves M, Dorsey FC, et al. (2012). Mitochondrial dysfunction in ataxia-telangiectasia Blood, 119: 1490-5001

[194] Fulop T, Le Page A, Fortin C, Witkowski JM, Dupuis G, Larbi A (2014). Cellular signaling in the aging immune system. Curr Opin Immunol, 29: 105-111. 
[195] Fulop T, Witkowski JM, Pawelec G, Alan C, Larbi A (2014). On the immunological theory of aging. Interdiscip Top Gerontol, 39: 163-176.

[196] Bektas A, Zhang Y, Lehmann E, Wood WH, Becker $\mathrm{KG}$, Madara K, et al. (2014). Age-associated changes in basal NF- $\kappa$ B function in human CD4+ T lymphocytes via dysregulation of PI3 kinase. Aging, 6: 957-969

[197] Reynolds LM, Taylor JR, Ding J, Lohman K, Johnson C, Siscovick D, et al. (2014). Age-related variations in the methylome associated with gene expression in human monocytes and T cells. Nat Commun, 5:5366

[198] Weinberg SE, Chandel NS (2015). Targeting mitochondria metabolism for cancer therapy. Nat Chem Biol, 11: 9-15.

[199] Mocchegiani E, Giacconi R, Cipriano C, et al. (2004). The variations during the circadian cycle of liver CD1dunrestricted NK1.1+TCR gamma/delta+ cells lead to successful ageing. Role of metallothionein/IL6/gp130/PARP-1 interplay in very old mice. Exp Gerontol. 39:775-88.

[200] Franceschi C, Bonafè M, Valensin S, Olivieri F, De Luca M, Ottaviani E, et al. (2000). Inflamm-aging. An evolutionary perspective on immunosenescence. Ann N Y Acad Sci, 908: 244-254.
[201] Fulop T, Larbi A, Wikby A, Mocchegiani E, Hirokawa K, Pawelec G (2005). Dysregulation of T-cell function in the elderly:scientific basis and clinical implications. Drugs Aging, 22: 589-603

[202] Heneka MT, Carson MJ, Khoury JE, Landreth GE, Brosseron F, Feinstein DL, et al. (2015). Neuroinflammation in Alzheimer's disease. Lancet Neurol, 14: 388-405.

[203] Anderson KM, Olson KE, Estes KA, Flanagan K, Gendelman HE, Mosley RL (2014). Dual destructive and protective roles of adaptive immunity in neurodegenerative disorders. Transl Neurodegener, 3: 25

[204] Saresella M, Calabrese E, Marventano I, Piancone F, Gatti A, Alberoni M, et al. (2011). Increased activity of Th-17 and Th-9 lymphocytes and a skewing of the postthymic differentiation pathway are seen in Alzheimer's disease. Brain Behav Immun, 25: 539-547

[205] Maciolek JA, Pasternak JA, Wilson HL (2014). Metabolism of activated T lymphocytes. Curr Opin Immunol, 27: 60-74 